contraste, o segundo no reconhecimento das necessidades econômicas da nação, até mesmo antes da sua independência.

Com tôda a justeza, é sustentado ser o Código do Comércio de 1850 uma expressão do liberalismo vitorioso no século dezenove. Essa adequação ao fenômeno político é, deveras, irrecusável, nela residindo, sem dúvida, uma das razões eminentes da longevidade do nosso diploma legal.

$O$ outro dado, que é pelo autor pôsto em destaque, bem evidencia a segurança com que a matéria é tratada. Na realidade, como em frase feliz foi ressaltado pelo ctedrático desta Escola, o "Código de comércio constituiu contínua e persistente aspiração de classe". Como salienta o autor, seu germe estava na lei de 1808, que abriu os portos do Brasil às nações amigas. Dado o primeiro passo, conseguido o primeiro triunfo, a classe dos comerciantes, cada vez mais pujante, lutou tenazmente pelo coroamento de seus desejos. O Código de 1850 representa, sem dúvida, o fecho de seu esfôrço. Não prometido pela constituição do império, o Código foi dos que primeiro surgiu, explicado pela tenacidade e pelo poderio da classe dos mercadores no Brasil.

3 - Dá em rápidos traços o depoimento de nossa doutrina, aliás depoimento unânime, sôbre a excelência do Regulamento 737, completo Código do Processo Civil, e que, travestido nos Códigos Estaduais, regeu o Processo Civil até o recente Código, de 1938.

4 - Por último, ressalta o autor a personalidade inolvidável do co-estaduano Irineu Evangelista de Souza, Barão e Visconde de Mauá. Representou êle a classe dos comerciantes na elaboração do Regulamento 737. Um dos mais operosos membros dessa classe, a quem o Brasil deve tanto, Mauá representou na comissão o espírito dêsses mercadores que exigiam a lei disciplinadora da atividade mercantil, como uma necessidade inadiável para o progresso da nação.

5 - Somos de parecer que o plenário aceite a tese, ressaltados o brilho e a segurança da dissertação.

\section{CENTENARIO DEL CODIGO DE COMERCIO BRASILEÑO}

\section{Sagunto P. Pérez Fontana*}

Professor de Direito Comercial na Faculdade de Direito de Montevideo.

Se cumple este año el centenario del Código de Comercio del Brasil, acontecimiento que debe ser celebrado no solamente por los juristas de ese país, sino también por los de los demás países, especialmente por los del nuestro y la Argentina, dada la preponderante influencia que dicho cuerpo de leyes tuvo en la preparación de nuestros respectivos Códigos de Comercio.

Corresponde a los autores brasileños hacer la historia del Código de Comercio de su país; historia que por otra parte ocupa lugar preponderante en los grandes tratados de Derecho Comercial como son de J. X. Carvalho de Mendonça, Waldemar Martins Ferreira y Alfredo Russel, para no citar sino los que nos son mas conocidos.

Sin perjuicio de ello y para rendir cumplido homenaje a quienes contribuyeron a la realización de esa obra que fué, en su tiempo, uno de los Códigos mas adelantados del mundo, haremos una breve y por lo tanto incompleta reseña del proceso de su preparación.

En primer término, debe mencionarse el nombre de José da Silva Lisboa, Vizconde de Cairu, reconocido como el primero de los comercialistas no solamente del Brasil sino de los que escribieron en lengua portuguesa, como lo destacó el eminente autor del Código de Comercio Portugués, Ferreira Borges, cuando afirmaba que sus obras "fueron código mercantil para Portugal hasta la publicación del Código de Comercio portugués". (1).

José da Silva Lisboa fué encargado el año 1809 de la redacción de un Código de Comercio, obra a la que dió principio pero no pudo terminar por haberle sido confiada la tarea de escribir la historia del Brasil hasta la declaración de la Independencia. Su nombre no figuró entre los integrantes de la Comisión nombrada el año 1832 para redactar el Proyecto de Código. No nos corresponde a nosotros entrar en detalles del porqué de esa postergación, episodio debidämente aclarado en su tiempo por los comentaristas brasileños. 
Por decreto de 14 de Marzo de 1832, la Regencia designó una Comisión encargada de redactar un proyecto de Código Mercantil lo que fué integrada por Antonio Paulino Limpo de Abreu, el Consejero José Antonio Lisboa, Ignacio Ratton, Guillermo Midosi y Honorio José Teixeira quien renunció siendo sustituído por Lorenzo Westin, Encargado de Negocios de Suecia.

La Comisión fué presidida, al principio, por Limpo de Abreu y después por José Clemente Pereira. Trabajó intensamente y presentó su Proyecto a la Cámara de Diputados el 14 de Agosto de 1834.

Prescindimos de la larga historia de su consideración, muchas veces interrumpida por los acontecimientos políticos hasta que el Código de Comercio fué aprobado por la ley n. ${ }^{\circ} 556$ de 25 de Junio de 1850 para entrar en vigencia el $1 .^{\circ}$ de Enero de 1851.

Aún antes de estar aprobado el Código, el Gobierno designó una Comisión encargada de preparar los reglamentos que hicieran fectiva la aplicación del Código. Presidida por el Ministro de Justicia Eusebio de Queiroz, estaba integrada por José Clemente Peticia Eusebio de Queiroz, estaba integrada por Jose Alberto Soares , Ireneo Evangelista de Souza, después Barón y Vizconde de Mó acontecimientos de la historia financiera y económica del Brasil y de la República Oriental del Uruguay.

Por sendos decretos de 25 de Noviembre de 1850 se aprobaron los reglamentos ns. 737 y 738, cuya importancia es equiparable a la del mismo Código, porque no solamente lo completan sino también porque en parte modifican las directrices fundamentales del mismo porque en parte modifican las directrices fundamentales del mismo como quedio y porque estuvieron largo tiempo en vigor, como sucedió con el que lleva el N. ${ }^{\circ} 737$, que se aplicó no solamente al proceso comercial sino también al Civil por habe
de Setiembre de $1890\left({ }^{2}\right)$.

$$
-\mathrm{O}
$$

Para la preparación del Código de Comercio la Comisión consultó los Códigos de Francia, España y Portugal y las obras de los más notables escritores de derecho comercial. "Procuró hacer un Código de Comercio acomodado a las circunstancias especiales del pueblo para el que es hecho".

Tomando en consideración las directivas de los Códigos de Comercio Español y Portugués trata de hacer del Código de Comercio un Código para los comercientes, es decir de marcada tendencia subun Código para los comercientes, es decir la falta de enumeración de los actos de comercio como contiene el Código de Comercio francés y otros que lo tomaron como modelo, sino también de muchas de sus disposiciones.

Fué propósito de los autores hacer de la matrícula de comerciantes el factor determinante de la calidad de tales. Así resulta de lo que establece el astículo $40^{\circ}$ : "Nadie es reputado comerciante, a los efectos de gozar de la protección que este Código establece en favor del comercio, si no se ha matriculado en alguno de los Tribunales de Comercio del Imperio y haga del Comercio su profesión habitual". $Y$ a mayor abundamiento el art. ${ }^{\circ}$ 9..$^{\circ}$ dispone que se presume que el ejercicio efectivo del comercio para todos los efectos legales, empieza desde la fecha de la publicación de la matrícula. Además en diversos artículos $(6,-7,-8,-10,-310,-908$ y 909 etc.) se refieren a los comerciantes matriculados)

A pesar de la tendencia marcadamente subjetiva del Código de Comercio, sus autores no pudieron sustraerse a la influencia que por su prestigio universal ejerció el Código de Comercio francés y la doctrina de ese país, no pudiendo afirmarse, por lo tanto que el del Brasil sea puramente un Código aplicable exclusivamente a los comerciantes y que solamente se considera tales a los que se hubieran inscripto en la matrícula. Ejemplo de ello son los artículos 909 y 18 y 19 del Título Unico que se refiere a los Tribunales de Comercio.

Faltó además una reglamentación adecuada del Registro Público de Comercio y de la matrícula de Comerciante, defecto de que adolecían sus modelos español y portugués ni que decir el francés que no conocía el Registro de Comercio.

Del mismo defecto adolecen los Códigos de Comercio argentino y uruguayo. La enorme extensión del vasto imperio y la poca población distribuída principalmente a lo largo del litoral atlántico, exceptuándose algunas comarcas mediterráneas erań también un obstáculo insalvable entonces para el cumplimiento de la obligación de matricular-se, aunque hubiera existido una adecuada reglamentación del Registro de Comercio.

El Reglamento n. 737 divide a los comerciantes en matriculados o no, reservando para los matriculados las prerrogativas y protección que el Código establece en favor del comercio (art. 15) previendo también la situación especial del fallido que no fuera comerciante matriculado (art. 16) y la contestación sobre la profesión habitual del comerciante matriculado (art. 17) así como la de la calidad del comerciante no matriculado (art. 18). Se llegaba así a la distinción del comerciante de derecho, o sea, el matriculado, del de hecho, el no matriculado).

Fué el mismo reglamento el que en los arts. 14 y 19 estableció e hizo una enumeración de actos de comercio, supliendo así la deliberada exclusión que hicieron los autores del Código. 
El citado reglamento enroló así al derecho comercial brasilero en la tendencia objetiva unanimente aceptada en esa época por la legislación codificada de todos los países.

Los autores del Código, como les aconteciera años más tarde a Eduardo Acevedo y Dalmacio Velez Sarsfield, ilustres autores del Código de Comercio para la Provincia de Buenos Aires, adoptado después por la Nación argentina el año 1862 y por la República Oriental del Uruguay en 1865, se encontraron con el obstáculo que representaba la falta de una adecuada codificación de las leyes civies, pues la vigente en el Brasil estaba constituída por un conglomerado de Ordenanzas, leyes, alvarás, assentos, resoluciones, reglamentos, etc., heredados de la época del Coloniaje, así como la legislación dictada después de la declaratoria de la independencia, situación que perduró hasta la entrada en vigor del admirable Código Civil. (Ley n. ${ }^{\circ} 3071$ del $1 .^{\circ}$ de Enero de 1916).

Para subsanar ese defecto los autores del Código incorporaron la reglamentación de los contratos y obligaciones mercantiles, en sendos títulos que comprenden la parte general, el mandato, comisión, compra-venta, permuta o cambio; locación, préstamo, fianzas y cartas de crédito, hipoteca y prenda; depósito, sociedades, letras, modos de extinción de las obligaciones y prescripción. (Títulos $\mathrm{V}$ a XVIII de la Parte I. - Esa incorporación de materia propiamente civil, obligada por las circunstancias, hizo decir al eximio Augusto Teixeira de Freitas $\left(^{3}\right)$ que los autores del Código de Comercio del Brasil imitando a sus hermanos se habían exorbitado incluyendo materias ajenas a la legislación comercial, "exorbitarao tamben - exorbitarao com demazia - mercantilizarao quasi tudo" y enumerando las materias que a su juicio debían quedar en el Código o sea: sociedades comerciales, letras de cambio, quiebras y jurisdicción comercial, lo que lógicamente lleva a la eliminación de la mayor parte de los títulos de la Parte I, como años más tarde lo hizo el legislador argentino al reformar el Código de Comercio de su país.

\section{$-0-$}

Los autores del Código de Comercio brasileño supieron utilizar la experiencia europea, tomando lo más importante de los Códigos y leyes que les sirvieron de modelo, por lo que el Código que redactaron fué uno de los más adelantados de su época y si contenía deficiencias, estas eran la consecuencia lógica del estado de los conocimientos generales y de la legislación.
La Comisión fiel a su propósito de hacer un Código acomodado. a las circunstancias especiales del pueblo a que debía aplicarse en varios capítulos originales introdujo la disciplina de ciertas actividades, cuya enumeración no se encuentra en los Códigos europeos. y si aparecen en los sud-americanos se debe a que tomaron como modelo el Código del Brasil.

Así, por ejemplo en el Libro I, Título III destinado a reglamentar la actividad de los agentes auxiliares de Comercio, se in cluyeron los capítulos III, V y VI referentes el III a los rematadores (Dos agentes de leiloes"; el $\mathrm{V}$ a los barraqueros y administradores de casas de depósito (Dos trapicheiros e administradores de armazens de deposito) y el VI a los porteadores y comisionistas de transporte (Dos conductores de generos e commissarios de transportes, capítulo donde no solamente se disciplina la profesión de porteador, sino también el contrato de transporte. Destina el Título IV que se compone de dos artículos 119 y 120) a los banqueros, definiéndolos como los comerciantes que tienen por profesión habitual de su comercio las operaciones llamadas de banco profesión

En la reglamentación de las distintas materias (art. 119). preocupó de llenar los vicios de que adolecían los códigos europeos, principalmente el francés. Fué así como los distintos capítulos destinados a las sociedades se incluyeron muchas disposiciones que no tienen antecedentes en otros Códigos. Además se disciplinó especialmente la llamada sociedad de capital e industria, creación original del Código de Comercio Portugués aunque sus antecedentes remotos deben buscarse en algún proyecto italiano y se reglamentan en forma detallada la disolución y liquidación de las sociedades.

Sería largo enumerar todas las disposiciones que el Código contiene y que significarán un proyecto para su época. Por otra parte, esa tarea tendría un interés relativo, desde que del primitivo Código es muy poco lo que queda vigente.

No transcurrieron muchos años desde la entrada en vigencia del Código de Comercio sin que se hiciera sentir la necesidad de reformar muchas de sus disposiciones, especialmente la reglamentación de las sociedades anónimas que era una de las partes más deficientes del Código.

El Brasil tomaba decidida y firmemente una orientación progresista en todas las actividades humanas y en el campo económico y financiero encontró un gran propulsor en Irineo Evangelista de Souza, más tarde Vizconde de Maua. Su influencia personal y la de sus empresas se extendió hasta el Río de influencia personal mente a la República Oriental del Uruguay donde fundó el Banco 
Maua, explotó estancias, instaló diques, etc. Su caída, como la de todos los colosos, fué estrepitosa.

El Código de Comercio a pesar de los adelantos que contenía, no se podía adaptar a las nuevas modalidades de los negocios que iban creando y haciendo necesaria la disciplina de sociedades con fines especiales, que requerían también la reglamentación especia de sus operaciones. Faltaba y era lógico que así fuera la reglade sus operaciones. quiebras respondían a un concepto vetusto del instituto.

quiebras respondian a un concepto todas las solicitudes del progreso Pero los bras las leyes necesarias para poner a tono la legislasupieron dictar las ley el desarrollo de las actividades. Es así que cion com el progreso y clades anónimas y sobre quiebras, para no la legislación sobre sociedades anonimas y sobre ques.

Además del Código de Comercio, del que como ya se dijo, es muy poco lo que queda vigente, por las grandes reformas introdumuy por leyes posteriores, principalmente sobre sociedades anónicidas por leyes posteriores, principalmen el Brasil una abundantísima mas letras de cambio y quiebras, rige en el Brasil una abundantima y renovada legislación, de la que solamente recordaremos las leyes y renovadivas a sociedades cooperativas, de responsabilidad. limitada, de relativas a sociedades cooperativas, seguros maritimos y terrestres, anos, transporte ferroviario y conotador, cheques, almacenes generales, transporte ferroviario y conocimiento de carga, marcas de fábrica y de comercio, patentes de invención, etc., duplicatas o contas assinadas, obligaciones o debentures y muchas otras.

De ese conjunto de leyes merecen destacarse la de 31 de Diciembre de 1908, que sustituyó todo el título décimo del Código relativo a las letras de cambio, notas promisorias y créditos mercantitivo a las letras de cambio, no 26 de Setiembre de 1940 sobre socieles; el decreto-ley n. ${ }^{\circ} 2.627$ de 26 de dades anónimas, que es una de las leyes más completas de 1945 sobre sociedades $y$

quiebras. Cuenta el Brasil con un Código del aire o "Código Brasileiro do
" aplicable a la aviación civil y comercial, instituído por el Decreto-lei de 8 de Junio de 1938.

La parte del Código que ha sufrido menos reformas es la relativa al derecho marítimo pudiendo mencionarse la reglamentación de la hipoteca naval y de los corredores marítimos.

$$
\text { - - - }
$$

Quienes, como el suscripto, son decididos partidarios de la unificación del derecho privado no pueden silenciar el valiosísimo aporte de la doctrina brasileña relativa a este debatido problema $\left({ }^{4}\right)$. te de la doctrina brasilena rearelli y Waldemar Martins Ferreira $\left(^{5}\right)$ que fué Augusto Teixeira de Freitas, el ilustre autor del Esboço de Código Civil y de los "Additamentos ao Codigo de Comercio", el precursor del movimiento unificador, en la propuesta hecha al Gobierno Imperial en la nota de 20 de Setiembre de 1867. En ese notable documento proponía la adopción de dos Códigos, uno general dividido en dos libros comprendiendo: el primero, la disciplina de las causas jurídicas, las personas, los bienes y los hechos y el segundo, los efectos jurídicos y un Código Civil compuesto de tres libros: el primero destinado a los efectos civiles, el segundo a los derechos personales y el tercero a los derechos reales.

La iniciativa fué acogida como "digna de toda consideración" por la Sección de Justicia del Consejo de Estado integrado por José Tomás Nabuco de Araújo, Francisco de Salles Torres Homen y el Vizconde de Jaquitinhonha $\left({ }^{6}\right)$, pero en definitiva fué desechada.

Teixeira de Freitas no concretó ningún proyecto de Código general ni tampoco terminó su notlabe Esboço que tanto influyó en la preparación del Código Civil Argentino.

Sus ideas tuvieron ampla difusión en el Brasil, siendo importante, tanto por el número como por el valimento de sus sostenedores, la corriente unificadora del derecho privado. La sola mención de los nombres de Brazilio Machado, Alfredo Valladão, Silva Costa, Coelho Rodrigues, Carlos de Carvalho, Didimo da Veiga, Saa Vianna, João Monteiro, Carvalho Mourão, Paulo de Lacerda, Gudesteu Pires, Waldemar Ferreira, Octavio Mendes y Carvalho de Mendonça, Alfredo Russel y Herculano Marcos Ingles de Souza $\left(^{7}\right)$ es suficiente para demonstrar el prestigio de que goza esa corriente doctrinaria y los esfuerzos que se han hecho para llevarla a la práctica.

En efecto, cuando el Gobierno presidido por Hermes de Fonseca encomendó a Herculano Marcos Inglez de Souza la preparación de un proyecto de Código de Comercio, este distinguido profesor presentó el 30 de Abril de 1912 dos proyectos, uno de Código de Cornercio y otro de enmiendas destinado a convertirlo en un Código de Derecho Privado, lo que hubiera podido tener andamiento porque el Brasil no contaba todavía con un Código Civil, que recién fué promulgado por la ley n. $^{\circ} 3071$ de $1 .^{\circ}$ de Enero de 1916. El proyecto de Inglez de Souza se discutió durante largos años pero no llegó a aprobarse.

\section{- -}

La rápida reseña que hemos hecho de los antecedentes del Código de Comercio del Brasil, del proceso de su elaboración y de la legislación que lo derogó en parte y sustituyó las disposiciones que no se adaptaban al ritmo de los negocios y al progreso material y 
jurídico alcanzado por el país, así como los estudios y esfuerzos realizados para llegar a la unificación del derecho privado, ponen en evidencia el afan de progreso y la cultura de los jurisconsultos brasileños, lo que justifica el puesto prominente que dicho país ocupa en materia de legislación en sus más variados aspectos.

El mismo juicio es aplicable a la doctrina brasileña y si nos abstenemos de citar nombres es para evitar incurrir en olvidos, aunque hay uno que es imposible silenciar porque ocupa el sitial de honor dentro de la literatura jurídico-comercial y es el de José Xavier Carvalho de Mendonça cuyo monumental Tratado de Direito Comercial Brasileiro es ya una obra clásica y pueda parangonarse con los Tratados escritos por los más reputados maestros europeus.

\section{$\mathrm{NOT} \mathrm{A} \mathrm{S}$}

1 - Princípios de direito mercantil de Silva Lisboa. ed. Cândido Mendes, Vol. 2, pg. 956, citado por J. X. Carvalho de Mendonca. Tratado de Direito Comercial brasileiro - $3 .^{\mathrm{a}}$ ed. T. I pg. 87.

2 - Sobre el proceso de la elaboración del Código de Comercio, y de los eglamentos, véase la obra citada de Carvalho de Mendonça, - Waldemar Mirtins Ferreira, Tratado de Direito Mercantil Brasileiro, T. I y As directrizies do Direito mercantil brasileiro.

3 - Augusto Teixeira de Freitas - Aditamentos ao Codigo do Comercio - Rio de Janeiro 1878 - Vol. I pg. XI y XII de la Advertência.

4 - Tullio Ascarelli - A evolução do Direito Commercial, en Revista de Direito Commercial, Vol. II pg. 33, nta. 41, citado por Waldemar Martins Ferreira, Instituções, 2. ${ }^{\mathrm{a}}$ ed. VoVl. I pg. 95.

5 - Waldemar Martins Ferreira - Instituções de Direito Commercial $2 .^{2}$ ed. Vol. I. n. ${ }^{\circ} 38$ pg. 94.

6 - Waldemar Martins Ferreira - Instituiçoes, cit. pg. 91.

7 - Citados por Waldemar Martins Ferreira - Instituições, pg. 95; Inglez de Souza; Direito Commercial, Preleções compiladas por Alberto Biolchini - 5. ${ }^{3}$ ed, pa. 33 y Alfredo Russell, Curso de Direito Commercial - Vol. I parte I, pg. 14.

\section{RELATÓRIO E PARECER}

Relator: PAULO BARBOSA LESSA

A tese do Prof. Sagunto Pérez Fontana reveste-se de singular importância, pois traça, com nitidez, a apreciação de mestre estrangeiro sôbre a nossa legislação comercial, e, em especial, sôbre o nosso Código de Comércio.

Amparando-se em fontes as mais fidedignas e autorizadas, o autor aprecia os traços gerais da sistemática mercantil brasileira, ressaltando as linhas mestras do diploma brasileiro e a sua linha de evolução.

Fazendo o levantamento histórico do diploma, acentuando as suas fontes históricas, traçando os veios decisivos da matéria codificada, revela-se o autor um mestre autêntico, já pela clareza da dissertação, já pela segurança da exposição.

Interessante é ressaltar a profissão de fé na unificação do direito privado e, mais que isso, o realce dado pelo autor à corrente unificadora brasileira. Convém, contudo, se diga do deslocamento do fulcro unificador brasileiro para a unificação parcial ou mai precisamente para o direito obrigacional. Os autores brasileiros que sustentam a unificação, já mais não pensam em unificação total completa do direito privado. Ficam na unificação parcial, da matéria obrigacional. E essa mesma unificação continua combatida pela corrente adversária, também composta de nomes autorizados.

Conforta a esta comissão especial o alto destaque contido no trabalho da personalidade de Augusto Teixeira de Freitas, civilista emérito, ainda não superado, em vigor, segurança e brilho, em nossa pátria. Teixeira de Freitas, cuja obra não conheceu a limitação das fronteiras, já que influiu decisivamente nos Códigos dos países irmãos, permanece, de fato, como um marco não ultrapassado no panorama da doutrina civilista do Brasil.

Isto pôsto, é parecer do relator seja o trabalho aprovado, ressaltada a segurança e o brilho da exposição. 